\title{
Phenotypic characterization of circulating tumor cells in triple negative breast cancer patients
}

\author{
Sofia Agelaki ${ }^{1,2}$, Melina Dragolia ${ }^{3}$, Harris Markonanolaki ${ }^{3}$, Saad Alkahtani ${ }^{4,5}$, \\ Christos Stournaras ${ }^{5}$, Vassilis Georgoulias ${ }^{3}$, Galatea Kallergi ${ }^{3,5}$ \\ ${ }^{1}$ Laboratory of Translational Oncology, School of Medicine, University of Crete, Voutes, Heraklion, Greece \\ ${ }^{2}$ Department of Medical Oncology, University General Hospital of Heraklion, Voutes, Heraklion, Greece \\ ${ }^{3}$ Laboratory of Tumor Cell Biology, School of Medicine, University of Crete, Voutes, Heraklion, Greece \\ ${ }^{4}$ Department of Zoology, Science College, King Saud University, Riyadh, Saudi Arabia \\ ${ }^{5}$ Department of Biochemistry, University of Crete Medical School, Voutes, Heraklion, Greece \\ Correspondence to: Galatea Kallergi, email: kalergi@med.voc.gr
}

Keywords: CTCS, HER2, estrogen receptor, progesteron receptor, EGFR

Received: August 01,2016 Accepted: November 22, $2016 \quad$ Published: December 24, 2016

\section{ABSTRACT}

Introduction: Patients with triple negative breast cancer (TNBC), are considered as a poor prognosis group for whom no targeted therapies are currently available. The aim of the present study was to phenotypically characterize their CTCs in order to explore potential therapeutic targets.

Methods: PBMC's cytospins were prepared from 45 early (before and after adjuvant chemotherapy), 10 metastatic TNBC and 21 hormone receptor (HR) -positive patients. The expression of Cytokeratins (CK), ER, PR, EGFR and HER2 on CTCs was assessed using immunofluoresence staining and ARIOL analysis.

Results: In early stage TNBC, ER, PR, HER2 and EGFR expressing-CTCs were detected in $24.4 \%, 24.4 \%, 20 \%$ and $40 \%$ of patients before the initiation of adjuvant chemotherapy, and in $17.8 \%, 13.3 \% 6.7 \%$ and $51.1 \%$ respectively after the completion of adjuvant treatment. Triple staining experiments revealed distinct subpopulations of CTC expressed HR, and ErbB family receptors. In patients with metastatic disease, the frequency of HER2+ CTCs was significantly increased compared to adjuvant setting $(60 \%$ vs $20 \%, \mathrm{p}=0.014)$. The presence of $\mathrm{CK}^{+} \mathrm{PR}^{-} \mathrm{CTCs}$, before adjuvant treatment was associated with reduced OS $(p=0.032)$ and DFI $(p=0.04)$. Furthermore, the frequency of ER-, PR- and HER2+ CTCs was higher in HR(+) than in TNBC tumors (57.1\%, $\mathrm{p}=0.006 ; 52.4 \%, \mathrm{p}=0.021$ and $52.38 \%, \mathrm{p}=0.009$, respectively).

Conclusions: The CTCs in patients with early TNBC are phenotypically heterogeneous based on the expression of HR, EGFR and HER2 both before and after the completion of adjuvant chemotherapy whereas the presence of HER2+ CTCs prevails during disease evolution. These findings could be of clinical relevance in terms of CTC targeting.

\section{INTRODUCTION}

Triple-negative breast cancer (TNBC) represents approximately $15 \%$ of all breast cancers, lacks expression of estrogen (ER) or progesterone (PR) receptor, and human epidermal growth factor receptor-2 (HER2) overexpression [1]. Triple negative tumors typically have high grade, elevated mitotic index, and present high levels of tumor cell apoptosis [2]. There is a significant overlap between TNBC and the molecularly defined basallike intrinsic subtype [3], since up to $80 \%$ of basal-like cancers are triple negative and approximately $70 \%$ of triple negative tumors are basal-like. EGFR and c-kit have been used as surrogates for the basal-like phenotype $[4,5]$. The basal-like phenotype and BRCA1 associated tumors also demonstrate expression of EMT-related molecules 
such as vimentin and laminin [6, 7]. Chemotherapy remains the standard treatment for TNBC $[1,8]$. Although patients with TNBC seem to achieve higher response rates to chemotherapy, this does not translate into superior progression free (PFS) or overall survival (OS) [6]. On the contrary, TNBC is responsible for the highest number of breast cancer-related deaths which is partly attributed to its unique biological characteristics and to the lack of approved targeted treatments for this subtype, highlighting the need for novel therapeutic approaches [9].

Circulating Tumor Cells (CTCs) hold significant prognostic and predictive information in patients with early or metastatic breast cancer [10-12]. Besides the value of CTC detection, the phenotypic and molecular characterization of CTCs can serve as a real time liquid biopsy [13] that can inform on alterations of the tumor's profile which may occur during the evolution of the disease. Several studies have shown a great phenotypic discordance between the primary tumor cells and CTCs especially in HER2 status [14-17]. It has been proposed that the phenotypic analysis of CTCs could reveal therapeutic targets on tumor cells that could be missed when analyzing the primary tumor $[15,18]$.

It has been recently shown lower CTC positivity rates in TNBC compared to the luminal subtypes possibly attributable to the EMT phenotype of CTCs in these patients [19] although other investigators failed to confirm this observation [20]. Nevertheless, CTC enumeration has been reported to be of prognostic relevance in patients with early stage TNBC [21], as well as in the neoadjuvant [22] and the metastatic setting [23]. However, the phenotypic characterization of CTCs in TNBC patients has not been addressed so far. The aim of the current study was a) to identify the expression pattern of ER, PR, HER2 and EGFR on CTCs of TNBC patients before and after adjuvant chemotherapy $b$ ) to delineate the phenotypic heterogeneity of CTCs in patients with early and metastatic TNBC and, finally c) to identify potential differences in the incidence of CTC phenotypes between patients with hormone receptor (HR) positive $(+)$ and TNBC.

\section{RESULTS}

\section{Expression of ER, PR, HER2 and EGFR on CTCs isolated from early stage TNBC patients}

Cytospins with the corresponding cell lines were used as positive and negative controls in every experiment (Figure 1) The expression of $\mathrm{CK}$ was investigated in PBMC s obtained from TNBC patients with early disease before and after the completion of adjuvant chemotherapy, using double CK/CD45 staining experiments (Figure 2A) It was shown that the total number of CK-positive patients,
MCF7 CONTROLS

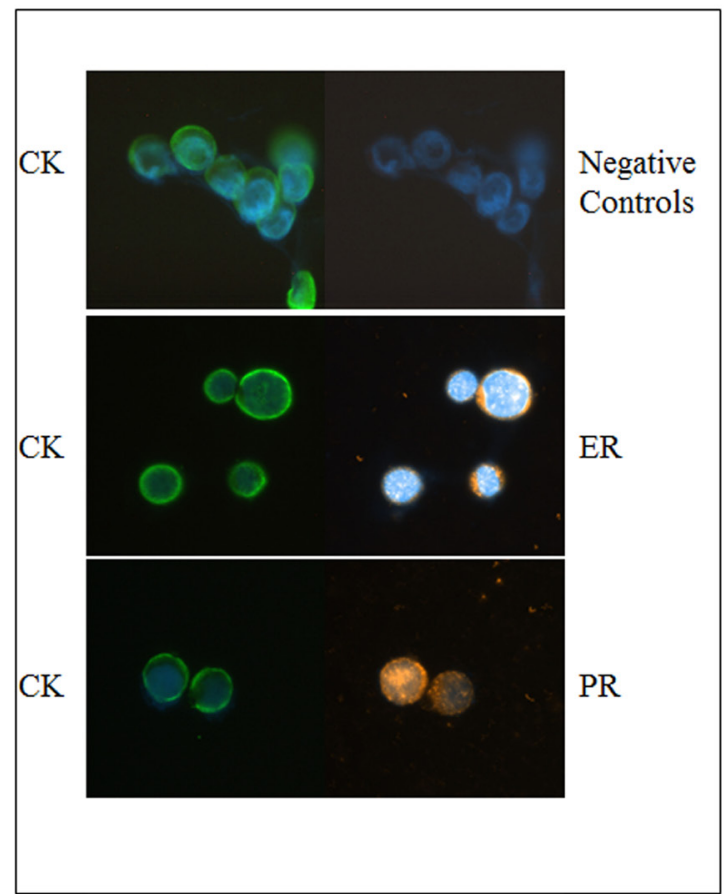

SKBR3 CONTROLS

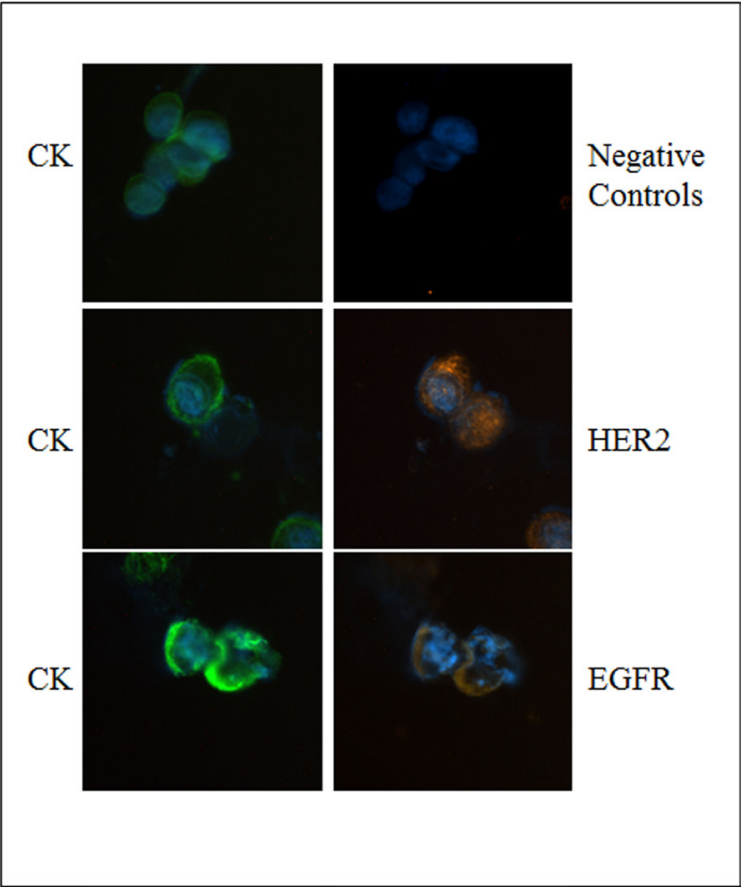

Figure 1: ER, PR, HER2 and EGFR expression in breast cancer cell lines. Representative MCF7 cells stained with pancytokeratin (CK) and ER or PR, analyzed by ARIOL microscopy (magnification X400). The SKBR3 cell line was used as positive and negative controls for CK along with HER2 or EGFR, respectively. 
as well as the mean percentage of CK-positive cells per patient, before and after treatment, was not significantly reduced. Indeed, 39 out of $45(86.6 \%)$ patients before and 37 out of $45(82.2 \%)$ patients after the completion of adjuvant treatment were characterized as CTC-positive, since they harvested at least 1 cell positive for at least one of the examined markers No statistical difference was observed in the total number of CTCs between the early and metastatic disease settings $(\mathrm{p}=0.876)$.

ER-positive CTCs (Figure 2B) were identified in 11 out of 45 patients $(24 \%)$ before and in $8(17.8 \%)$ after chemotherapy (Figure 3A). Among CTC-positive patients, the incidence of ER-positive CTCs before and after chemotherapy was $44 \%$ and $38.1 \%$ respectively (Figure 3B). The mean percentage of ER positive CTCs per CKpositive patient was $27.9 \%$ before and $35 \%$ after treatment $(\mathrm{p}=0.334$; Figure $3 \mathrm{C})$.

Similar positivity rates were observed for PRpositive CTCs (Figure 2B) [24.4\% (11 out of 45 patients) and $13.3 \%$ ( 6 out of 45 ), before and after chemotherapy, respectively] (Figure 3A); furthermore, among patients with detectable CTCs, the corresponding numbers were $33.3 \%$ and $23.1 \%$, respectively (Figure $3 \mathrm{~B}$ ). The mean percentage of CTCs expressing PR per CK-positive patient was $22.4 \%$ before and $14.9 \%$ after treatment $(p=0.466$; Figure $3 \mathrm{C}$ ). There was a significant correlation between the proportion of ER- and PR-positive CTCs $(p=0.016)$ before the initiation of adjuvant treatment.

The frequency of HER2-positive CTCs (Figure 2B) was decreased $(\mathrm{p}=0.05)$ after treatment [in 9 out of 45 patients $(20 \%)$ pre-, and in 3 out of 45 patients (6.7\%) post-adjuvant chemotherapy] (Figure 3A). Among CTC-positive patients, the corresponding percentages were $34.6 \%$ and $11.1 \%$, before and after chemotherapy, respectively (Figure 3B). Furthermore, the mean percentage of HER2-expressing CTCs/patient was also significantly reduced $(30.4 \%$ at baseline and 5.0\% after adjuvant chemotherapy; $p=0.011$ ) (Figure 3C) while the number of HER2-/CK+ CTCs was increased after the completion of adjuvant therapy from $69.55 \%$ to $94.97 \%$ $(p=0.013)$. The median expression is also shown in Figure 3D. The quantification of HER2 expression in MCF7 SKBR3 and patients' CTCs ( $\mathrm{n}=5$ patients) is shown in Figure 2C.

EGFR-expressing CTCs were identified in 18 out of 45 patients $(40 \%)$ before the initiation of adjuvant chemotherapy and in 23 out of 45 patients (51.1\%) after treatment (Figure 3A). Among the patients with detactable

A

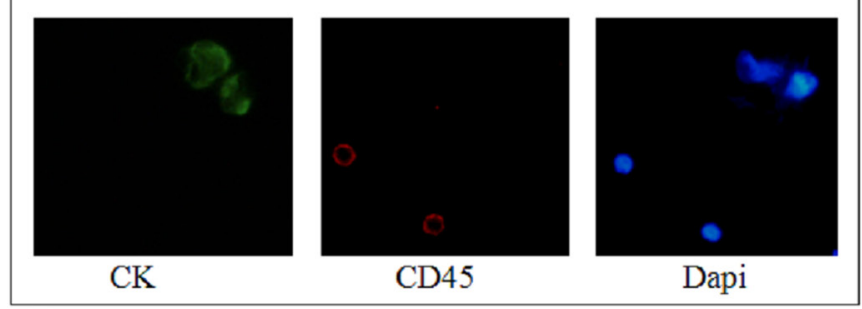

C

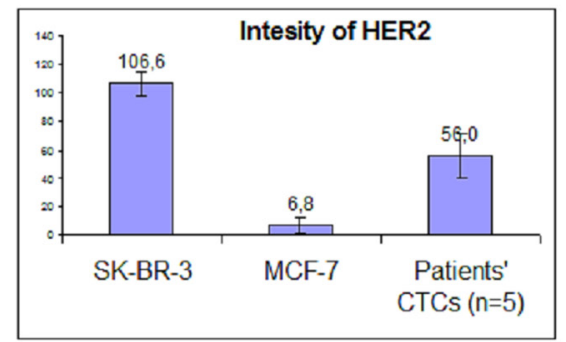

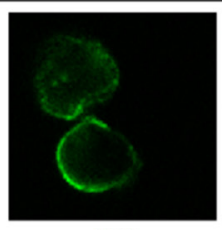

CK

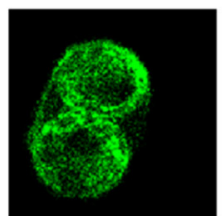

CK

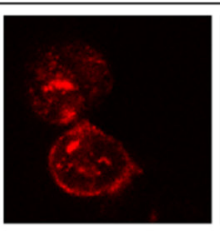

ER

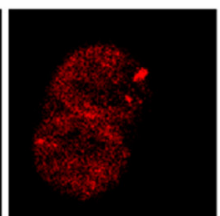

PR

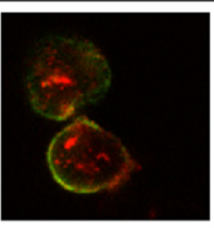

OVERLAY

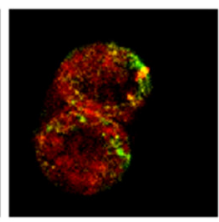

OVERLAY

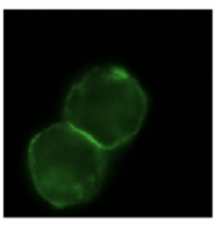

CK

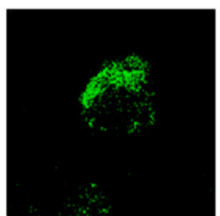

CK

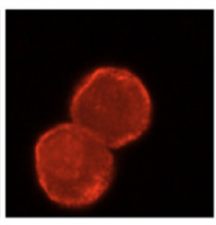

HER2

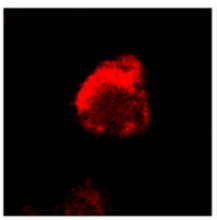

EGFR

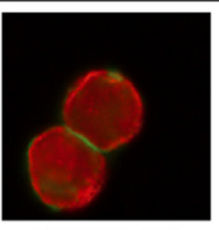

OVERLAY

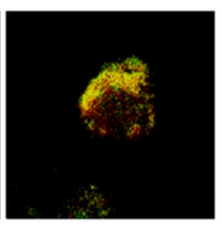

OVERLAY

Figure 2: ER, PR HER2 and EGFR staining in TNBC patients. A. Representative CK+/CD45- CTCs from TNBC patients analyzed by ARIOL microscopy (magnification X400) and Dapi staining; B. Representative images from Confocal laser scanning microscopy (magnification X60) of TNBC patients' CTCs stained with CK along with either ER, PR, HER2 or EGFR; C. Quantification of HER2 intensity in MCF7, SKBR3 and patients' CTCs. 
CTCs, EGFR expression before and after chemotherapy was observed in $78.3 \%$ and $82.1 \%$, respectively (Figure 3B). The mean percentage of EGFR-expressing CTCs was $67.2 \%$ before and $76.5 \%$ after treatment $(p=0.442$; Figure 3C). The median expression per patient for EGFR-positive CTCs was high both before (95.2\%) and after (100\%) treatment (Figure 3D). The number of CTCs isolated from TNBC patients for each phenotype is shown in Table 1.

To identify the potential co-expression of hormone receptors with ErbB family receptors at the single cell level, triple staining experiments for $\mathrm{CK} / \mathrm{ER} / \mathrm{EGFR}$, $\mathrm{CK} / \mathrm{ER} / \mathrm{HER} 2, \mathrm{CK} / \mathrm{PR} / \mathrm{EGFR}$ and $\mathrm{CK} / \mathrm{PR} / \mathrm{HER} 2)$ were performed after negative immunomagnetic isolation of CTCs. No co-expression was observed for EGFR and HR as it is shown in Figure 4A and Figure 4B where CK/ER/ EGFR staining revealed that distinct subpopulations were identified in individual patients. On the other hand, in 3 patients, HER2 was co-expressed with ER (Figure 3D), whereas HER2 and PR co-expression was not evident. In addition in order to reassure that the cells characterized as CTCs after immunomagnetic isolation are CD45-negative we performed triple staining experiments with anti-CK/ CD45/EGFR antibodies (Figure 4C).

\section{A}

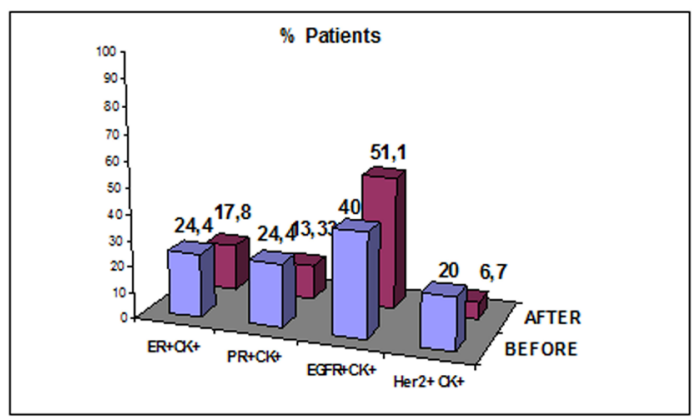

C

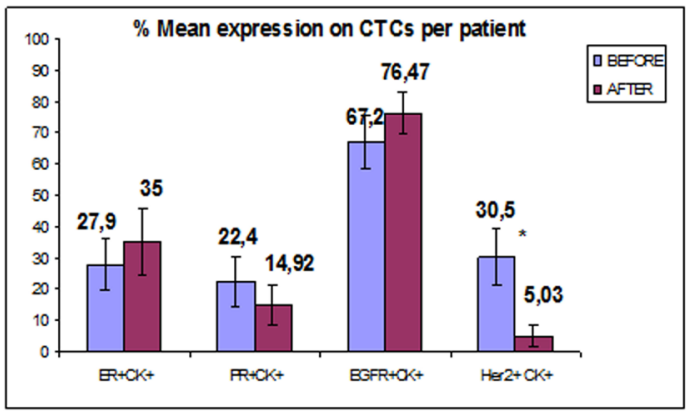

\section{Phenotypic characterization of CTCs in patients with metastatic TNBC}

To identify potential differences in CTC phenotype between early and metastatic TNBC patients, double staining experiments were also performed in 10 CTCpositive patients with metastatic disease before the initiation of any systemic treatment. ER-positive CTCs were observed in $4(40 \%)$ out of 10 patients compared to $44 \%$ in patients with early stage disease. Similarly, the percentage of ER-negative CTCs per patient was not significantly different in metastatic compared to early patients (72\% vs 74\%; $\mathrm{p}=0.082$ ) (Figure 5A).

PR-expressing CTCs were identified in 4 out of 10 (40\%) metastatic and in $33.3 \%$ patients with early breast cancer. The percentage of PR-positive CTCs per patient was not statistically different between the two settings (34\% vs $22.3 \%$ respectively) ( $p=0.231$; Figure $5 B$ ).

HER2-expressing CTCs were detected in 6 out of 10 $(60 \%)$ patients with metastatic disease and in 9 out of 26 $(34.6 \%)$ with early stage disease. Furthermore, there was a significantly increased number of HER2-expressing CTCs in patients with metastatic compared to patients with early

B

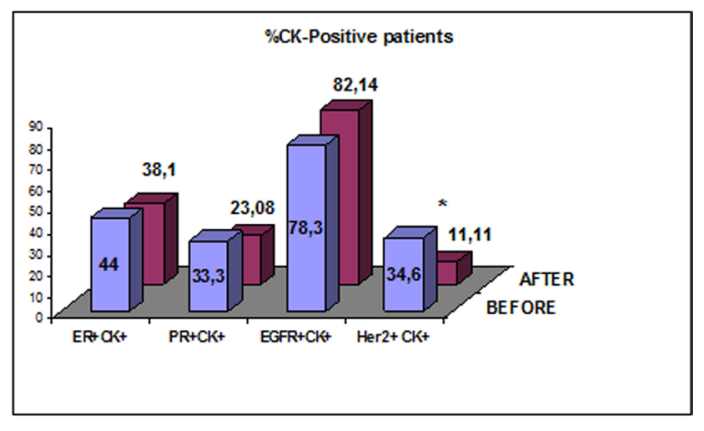

$\mathrm{D}$

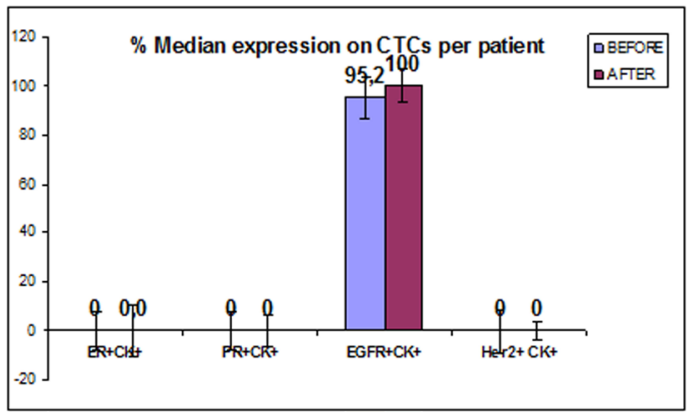

Figure 3: ER, PR, HER2 and EGFR expression on CTCs isolated from TNBC patients before and after adjuvant chemotherapy. A. Proportion of patients with $\mathrm{ER}^{+} \mathrm{CK}^{+}, \mathrm{PR}^{+} \mathrm{CK}^{+}, \mathrm{HER} 2^{+} \mathrm{CK}^{+}$and $\mathrm{EGFR}^{+} \mathrm{CK}^{+}$before and after adjuvant chemotherapy; B. Proportion of patients with ER, PR, HER2 and EGFR-positive CTCs, among the CK-positive TNBC patients; C. Proportion of CTCs with ER, PR, HER2 and EGFR-expressing CTCs per patient before and after treatment; D. \% Median expression of ER, PR, HER2 and EGFR-expressing CTCs per patient before and after treatment. 


\section{EARLY TNBC PATIENTS}

\begin{tabular}{|c|c|c|c|c|c|c|c|c|c|c|c|c|c|c|c|c|}
\hline \multirow[t]{2}{*}{ PATIENTS } & \multicolumn{8}{|c|}{$\begin{array}{c}\text { CTCS' PHENOTYPE BEFORE } \\
\text { CHEMOTHERAPY }\end{array}$} & \multicolumn{8}{|c|}{ CTCS' PHENOTYPE AFTER CHEMOTHERAPY } \\
\hline & $\mathbf{E R}^{+}$ & ER $^{-}$ & $\mathbf{P R}^{+}$ & $\mathbf{P R}^{-}$ & $\mathrm{EGFR}^{+}$ & EGFR- & Her2 $^{+}$ & Her2- & $\mathbf{E R}^{+}$ & ER $^{-}$ & $\mathbf{P R}^{+}$ & PR- & EGFR $^{+}$ & EGFR- & Her2 $^{+}$ & Her2- \\
\hline 1 & 1 & 21 & 0 & 1 & 0 & 1 & 1 & 0 & 1 & 3 & 0 & 1 & 1 & 0 & 0 & 0 \\
\hline 2 & 1 & 1 & 1 & 2 & 40 & 2 & 1 & 3 & 0 & 2 & 0 & 3 & 0 & 0 & 0 & 0 \\
\hline 3 & 0 & 0 & 0 & 2 & 2 & 0 & 1 & 0 & 0 & 1 & 0 & 1 & 0 & 0 & 0 & 0 \\
\hline 4 & 0 & 0 & 0 & 0 & 0 & 0 & 0 & 0 & 1 & 0 & 0 & 0 & 2 & 1 & 0 & 0 \\
\hline 5 & 1 & 0 & 5 & 5 & 1 & 0 & 0 & 6 & 0 & 2 & 0 & 3 & 1 & 1 & 2 & 14 \\
\hline 6 & 0 & 4 & 1 & 2 & 0 & 0 & 1 & 1 & 0 & 0 & 0 & 0 & 0 & 0 & 0 & 0 \\
\hline 7 & 0 & 0 & 0 & 0 & 0 & 0 & 0 & 0 & NS & NS & NS & NS & NS & NS & NS & NS \\
\hline 8 & 0 & 0 & 0 & 0 & 0 & 0 & 0 & 0 & 0 & 0 & 1 & 3 & 2 & 0 & 0 & 1 \\
\hline 9 & 0 & 3 & 0 & 3 & 5 & 0 & 0 & 3 & 0 & 3 & 0 & 3 & 2 & 0 & 0 & 3 \\
\hline 10 & 0 & 1 & 0 & 3 & 0 & 0 & 0 & 0 & 1 & 0 & 0 & 1 & 0 & 0 & 0 & 5 \\
\hline 11 & 0 & 0 & 0 & 2 & 0 & 0 & 0 & 0 & 0 & 0 & 0 & 3 & 0 & 0 & 0 & 3 \\
\hline 12 & 0 & 0 & 0 & 7 & 0 & 0 & 0 & 0 & 1 & 0 & 0 & 0 & 2 & 2 & 0 & 3 \\
\hline 13 & 1 & 0 & 0 & 1 & 6 & 1 & 18 & 0 & 0 & 1 & 0 & 6 & 1 & 1 & 0 & 0 \\
\hline 14 & 0 & 1 & 0 & 2 & 0 & 0 & 0 & 0 & 0 & 0 & 0 & 6 & 2 & 0 & 0 & 3 \\
\hline 15 & 1 & 5 & 4 & 0 & 1 & 1 & 0 & 1 & 0 & 0 & 0 & 0 & 1 & 1 & 0 & 0 \\
\hline 16 & 0 & 0 & 0 & 0 & 1 & 1 & 0 & 7 & 0 & 0 & 1 & 0 & 0 & 0 & 0 & 2 \\
\hline 17 & 0 & 1 & 0 & 1 & 1 & 0 & 0 & 2 & NS & NS & NS & NS & NS & NS & NS & NS \\
\hline 18 & 0 & 0 & 0 & 2 & 1 & 0 & 0 & 0 & NS & NS & NS & NS & NS & NS & NS & NS \\
\hline 19 & 0 & 0 & 1 & 7 & 0 & 0 & 1 & 0 & 0 & 0 & 0 & 0 & 3 & 0 & 0 & 1 \\
\hline 20 & 0 & 1 & 0 & 4 & 1 & 0 & 0 & 0 & 0 & 0 & 0 & 0 & 0 & 0 & 0 & 0 \\
\hline 21 & 0 & 0 & 0 & 0 & 0 & 0 & 0 & 0 & 0 & 0 & 0 & 0 & 0 & 0 & 0 & 2 \\
\hline 22 & 0 & 0 & 0 & 0 & 1 & 0 & 0 & 2 & 1 & 0 & 0 & 2 & 3 & 0 & 0 & 4 \\
\hline 23 & 0 & 2 & 0 & 75 & 0 & 2 & 0 & 1 & 0 & 1 & 0 & 1 & 0 & 0 & 0 & 1 \\
\hline 24 & 1 & 1 & 0 & 1 & 0 & 0 & 0 & 3 & 1 & 0 & 3 & 4 & 1 & 0 & 0 & 0 \\
\hline 25 & 0 & 1 & 0 & 1 & 2 & 0 & $\mathbf{0}$ & 1 & 0 & 0 & 0 & 3 & 0 & 1 & 0 & 1 \\
\hline 26 & 0 & 0 & 1 & 0 & 0 & 0 & 0 & 0 & 0 & 0 & 0 & 1 & 1 & 0 & 0 & 1 \\
\hline 27 & 0 & 12 & 0 & 62 & 7 & 0 & 15 & 0 & 0 & 6 & 0 & 4 & 2 & 0 & 4 & 1 \\
\hline 28 & 0 & 0 & 0 & 8 & 0 & 0 & 0 & 0 & 0 & 0 & 0 & 5 & 3 & 0 & 0 & 2 \\
\hline 29 & 0 & 0 & 0 & 1 & 0 & 0 & 0 & 1 & 0 & 0 & 0 & 6 & 2 & 0 & 0 & 5 \\
\hline 30 & 0 & 0 & 0 & 2 & 0 & 0 & 0 & 0 & 0 & 0 & 0 & 0 & 1 & 3 & 0 & 0 \\
\hline 31 & 23 & 18 & 9 & 1 & 0 & 3 & 0 & 1 & 0 & 0 & 0 & 0 & 7 & 3 & 1 & 2 \\
\hline 32 & 0 & 0 & 0 & 1 & 0 & 1 & 0 & 1 & 1 & 0 & 1 & 0 & 0 & 0 & 0 & 1 \\
\hline 33 & 0 & 4 & 2 & 1 & 0 & 0 & 0 & 0 & 0 & 0 & 0 & 4 & 5 & 0 & 0 & 1 \\
\hline 34 & 0 & 0 & 0 & 2 & 0 & 0 & 0 & 2 & 0 & 25 & 0 & 10 & 1 & 1 & 0 & 8 \\
\hline
\end{tabular}

(Continued) 


\begin{tabular}{|c|c|c|c|c|c|c|c|c|c|c|c|c|c|c|c|c|}
\hline \multirow[t]{2}{*}{ PATIENTS } & \multicolumn{8}{|c|}{$\begin{array}{c}\text { CTCs' PHENOTYPE BEFORE } \\
\text { CHEMOTHERAPY }\end{array}$} & \multicolumn{8}{|c|}{ CTCS' PHENOTYPE AFTER CHEMOTHERAPY } \\
\hline & $\mathbf{E R}^{+}$ & ER $^{-}$ & $\mathbf{P R}^{+}$ & PR & EGFR $^{+}$ & EGFR $^{-}$ & Her2 $^{+}$ & Her 2- & $\mathbf{E R}^{+}$ & $\mathbf{E R}^{-}$ & $\mathbf{P R}^{+}$ & $\mathbf{P R}^{-}$ & EGFR $^{+}$ & EGFR- $^{-}$ & Her $^{+}$ & Her2- \\
\hline 35 & 0 & 0 & 0 & 0 & 0 & 0 & 0 & 0 & 0 & 0 & 2 & 2 & 1 & 0 & 0 & 1 \\
\hline 36 & 2 & 6 & 0 & 5 & 4 & 6 & 3 & 0 & 0 & 3 & 0 & 0 & 0 & 0 & 0 & 1 \\
\hline 37 & 0 & 1 & 2 & 0 & 0 & 0 & 0 & 2 & NS & NS & NS & NS & NS & NS & NS & NS \\
\hline 38 & 1 & 0 & 1 & 0 & 0 & 0 & 0 & 1 & 0 & 0 & 0 & 1 & 0 & 0 & 0 & 0 \\
\hline 39 & 0 & 0 & 0 & 0 & 0 & 0 & 0 & 0 & 0 & 0 & 0 & 2 & 0 & 0 & 0 & 4 \\
\hline 40 & 0 & 1 & 0 & 0 & 1 & 0 & 0 & 0 & 0 & 3 & 1 & 0 & 6 & 0 & 0 & 3 \\
\hline 41 & 16 & 1 & 0 & 2 & 3 & 1 & 0 & 1 & 0 & 3 & 0 & 4 & 0 & 1 & 0 & 0 \\
\hline 42 & 0 & 0 & 0 & 0 & 0 & 0 & 0 & 0 & NS & $\mathrm{NS}$ & NS & $\mathrm{NS}$ & NS & NS & NS & NS \\
\hline 43 & 0 & 3 & 0 & 0 & 1 & 0 & 0 & 0 & 0 & 0 & 0 & 0 & 0 & 0 & 0 & 0 \\
\hline 44 & 1 & 0 & 14 & 5 & 0 & 1 & 1 & 0 & 0 & 1 & 0 & 0 & 1 & 0 & 0 & 0 \\
\hline 45 & 0 & 1 & 0 & 1 & 1 & 1 & 0 & 1 & 3 & 1 & 0 & 1 & 0 & 0 & 0 & 0 \\
\hline
\end{tabular}

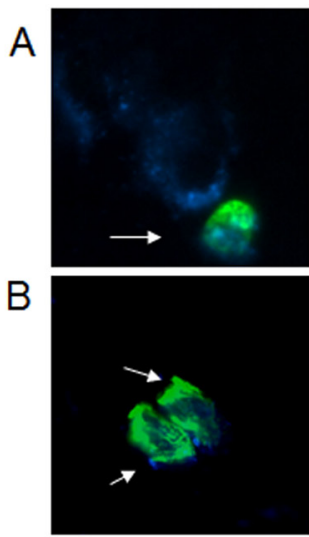

CK

C

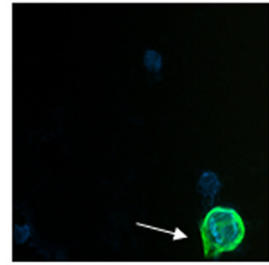

CK

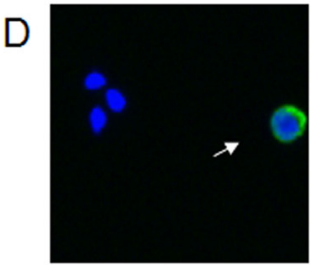

CK
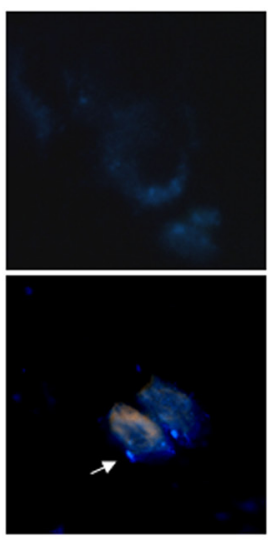

ER

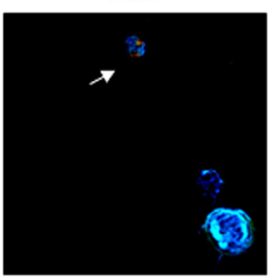

$\mathrm{CD} 45$

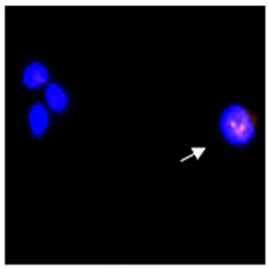

ER

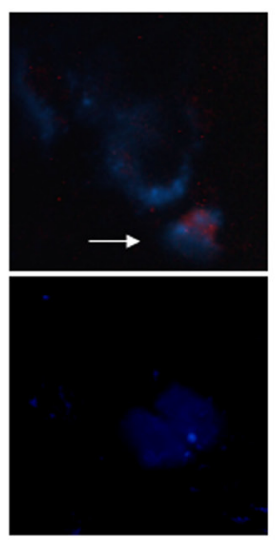

EGFR

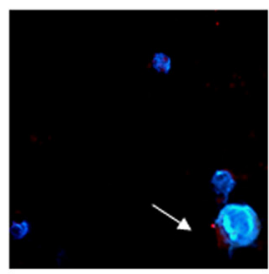

EGFR

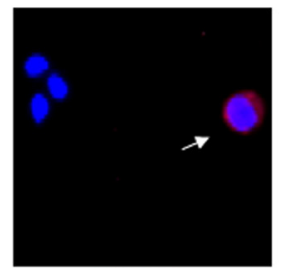

HER2

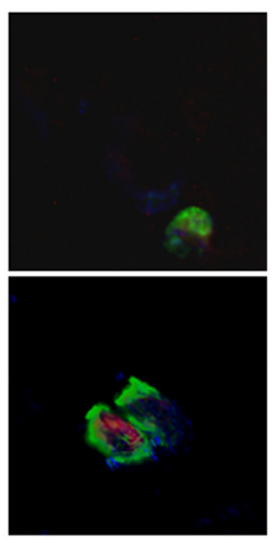

Overlay

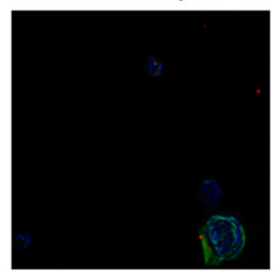

Overlay

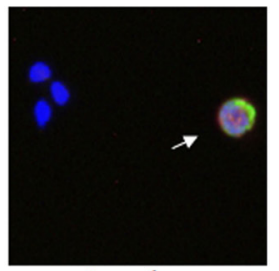

Overlay

Figure 4: Phenotypic characterization of CTCs after Immumomagnetic separation. Representative triple (CK/ER/EGFR and $\mathrm{CK} / \mathrm{ER} / \mathrm{HER} 2$ ) immunofluorescence staining of CTCs isolated from early stage TNBC patients using ARIOL microscopy (magnification X400). A. CTC positive for CK/EGFR and negative for ER; B. CTC positive for CK/ER and negative for EGFR; C. CTC positive for CK, EGFR and negative for CD45; D. CTC positive for CK/HER2/ER. 
stage disease ( $51 \%$ vs $30.5 \%$, respectively $p=0.014$; Figure 5B).

EGFR-positive CTCs were also detected in $60 \%$ and $78.3 \%$ of patients with metastatic and early stage disease, respectively (Figure 5A). The percentage of EGFRpositive CTCs was high but not significantly different $(p=0.337$; Figure $5 B)$ in both settings.

The median expression of ER, PR, HER2 and EGFR-expressing CTCs per patient as well as the number of the corresponding CTCs in the metastatic setting are presented in Figure 5C and Table 2, respectively.

\section{ER, PR, HER2 and EGFR expression on CTCs from patients with $\mathrm{HR}(+)$ breast cancer}

The expression of the above markers was also assessed on CTCs isolated from 21 patients with $\mathrm{HR}(+)$ early breast cancer before the initiation of adjuvant treatment. ER-expressing CTCs were detected in 12 out of 21 patients $(57.1 \%)$ with $\mathrm{HR}(+)$ tumors compared to TNBC patients $(24.4 \% ;(p=0.232)$ (Figure 6A). Among the CK-positive patients, ER-positive CTCs were identified in 12 out of 15 patients $(80 \%)$ while the respective percentage for TNBC was $44 \%(p=0.313$; Figure $6 B)$. The mean percentage of ER-expressing CTCs per patient was significantly higher in $\mathrm{HR}(+)$ patients compared to TNBC patients [60.1\% versus $27.9 \%$, respectively] $(p=0.006$; Figure 6C).

Similarly, PR-expressing CTCs were identified in 11 out of $21 \mathrm{HR}(+)$ patients $(52.4 \%)$ compared to $24.4 \%$ in TNBC ( $p=0.036$; Figure 6A). Among the CK-positive patients, PR was expressed in $69 \%$ [11 out of 16 patients] with $\mathrm{HR}(+)$ tumors vs $33.3 \%$ in patients with TNBC $(p=0.016$; Figure 6B). The percentage of PR-expressing CTCs was $43.9 \%$ in patients with $\mathrm{HR}(+)$ disease and $22.4 \%$ in TNBC patients ( $\mathrm{p}=0.028$; Figure $6 \mathrm{C})$.

HER2-expressing CTCs were detected in 11 out of 21 patients $(52.4 \%)$ with $\mathrm{HR}(+)$ tumors compared to $20 \%$ of TNBC patients $(p=0.023)$. Among the patients with detectable CTCs the respective numbers were $68.8 \%$ (11 out of 16 patients) in $\mathrm{HR}(+)$ and $34.6 \%$ in TNBC patients $(\mathrm{p}=0.055$; Figure 5B). Moreover, the percentage of CTCs expressing HER2 was also significantly higher $(p=0.029)$ in patients with $\mathrm{HR}(+)$ tumors compared to patients with TNBC tumors(43.1\% vs 30.5\%) (Figure 5C).

In the whole cohort of patients, EGFR-expressing CTCs were detected in $42.9 \%$ (9 out of 21 ) vs $40 \%$ in $\mathrm{HR}+$ and $\mathrm{TNBC}$ subjects $(\mathrm{p}=0.785)$ respectively (Figure 5A). However, among the CK-positive patients, EGFRexpressing CTCs were detected in 9 out of 17 patients $(52.9 \%)$ with $\mathrm{HR}(+)$ - disease compared to $78.3 \%$ of TNBC patients $(\mathrm{p}=0.037)$ (Figure $5 \mathrm{~B})$. The percentage of CTCs

A

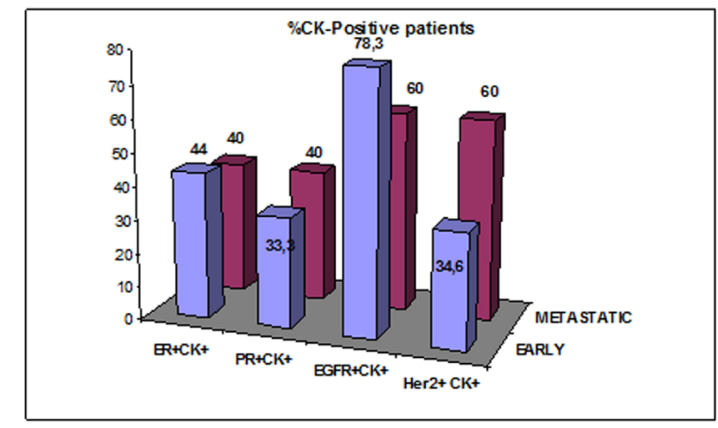

B

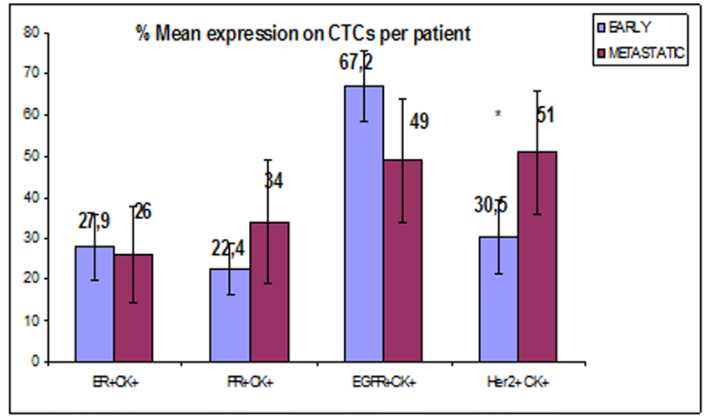

C

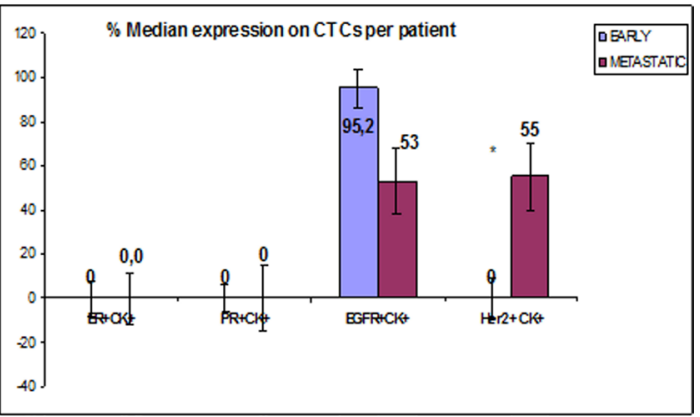

Figure 5: ER, PR, HER2 and EGFR expression on CTCs isolated from early vs metastatic TNBC patients. A. Percentage of patients that expressed double positive cells of each phenotype $\left(\mathrm{ER}^{+} \mathrm{CK}^{+}, \mathrm{PR}^{+} \mathrm{CK}^{+}, \mathrm{HER} 2^{+} \mathrm{CK}^{+}\right.$and $\left.\mathrm{EGFR}^{+} \mathrm{CK}^{+}\right)$in early vs metastatic setting; B. \% Mean expression of ER, PR, HER2 and EGFR-expressing CTCs per patient in early vs metastatic setting; C. \% Median expression of ER, PR, HER2 and EGFR-expressing CTCs per patient in early vs metastatic setting. 
Table 2: CTCs' phenotype in metastatic TNBC patients

\begin{tabular}{lcccccccc}
\hline \multicolumn{7}{c}{ CTCs' $^{\prime}$ PHENOTYPE IN METASTATIC TNBC PATIENTS } \\
\hline PATIENTS & ER $^{+}$ & ER $^{-}$ & PR $^{+}$ & PR $^{-}$ & EGFR $^{+}$ & EGFR $^{-}$ & Her2 $^{+}$ & Her2 $^{-}$ \\
\hline 1 & 0 & 1 & 0 & 3 & 1 & 0 & 1 & 0 \\
2 & 1 & 0 & 1 & 0 & 4 & 1 & 2 & 2 \\
3 & 2 & 4 & 3 & 4 & 0 & 0 & 1 & 0 \\
4 & 0 & 13 & 0 & 2 & 0 & 1 & 3 & 0 \\
5 & 0 & 1 & 0 & 1 & 3 & 8 & 0 & 0 \\
6 & 1 & 1 & 0 & 17 & 1 & 0 & 0 & 1 \\
7 & 0 & 2 & 0 & 1 & 7 & 1 & 0 & 1 \\
8 & 0 & 1 & 1 & 0 & 1 & 0 & 4 & 2 \\
9 & 0 & 1 & 0 & 1 & 0 & 1 & 0 & 1 \\
10 & 3 & 1 & 9 & 0 & 0 & 0 & 2 & 0 \\
\hline
\end{tabular}

A

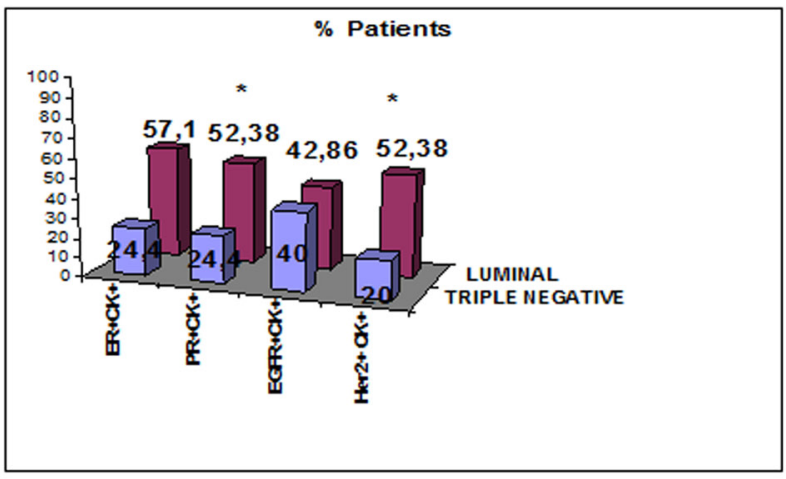

C

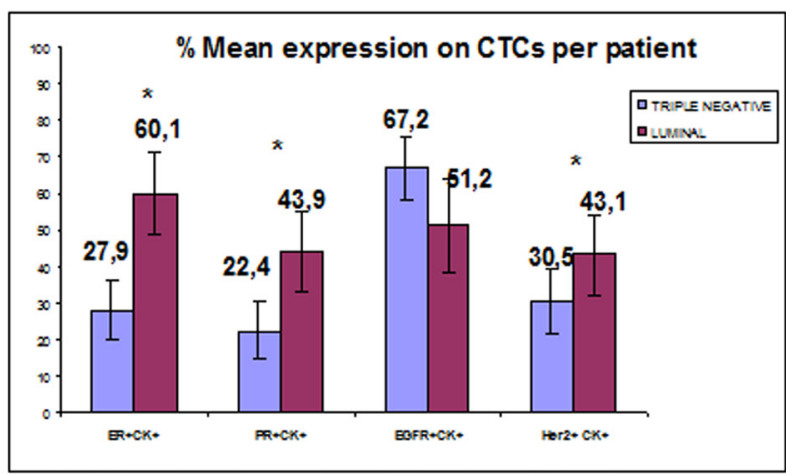

B

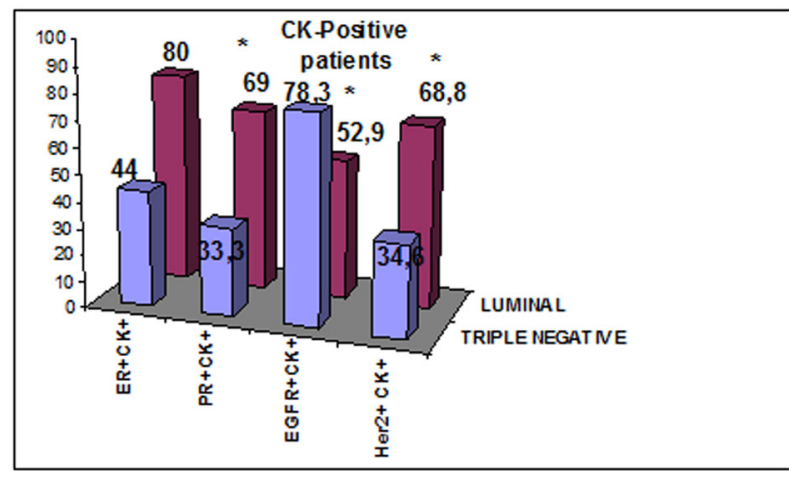

$\mathrm{D}$

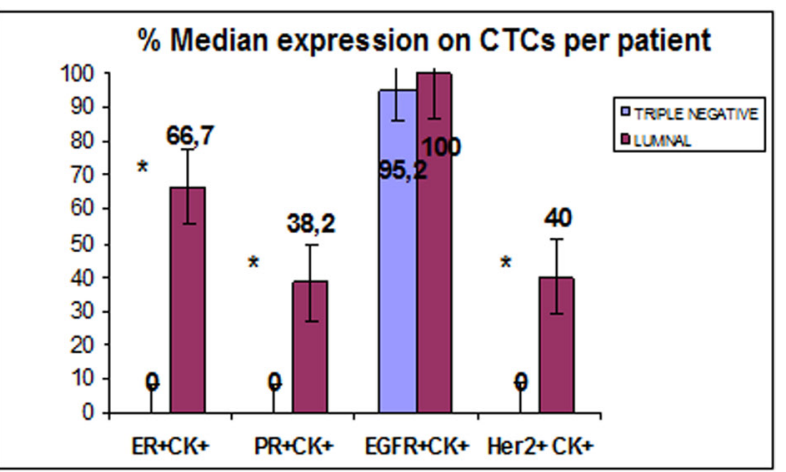

Figure 6: Comparison of ER-, PR-, HER2- and EGFR-expressing CTCs detected in TN and HR-positive breast cancer patients before adjuvant chemotherapy. A. Proportion of patients with $\mathrm{ER}^{+} \mathrm{CK}^{+}, \mathrm{PR}^{+} \mathrm{CK}^{+}, \mathrm{HER}^{+} \mathrm{CK}^{+}$and $\mathrm{EGFR}^{+} \mathrm{CK}^{+}$in $\mathrm{TN}$ and HR-positive patients; B. Proportion of patients with ER, PR, HER2 and EGFR-positive CTCs, among the CK-positive TN and HR-positive patients; C. Proportion of CTCs with ER, PR, HER2 and EGFR-expression inTNBC and HR-positive patients; D. Median expression of ER, PR, HER2 and EGFR-expressing CTCs per TNBC and HR-positive patients 
expressing EGFR per patient was $51.2 \%$ versus $67.2 \%$ in the two different groups of patients ( $p=0.47$; Figure $5 \mathrm{C}$ ).

The median expression of each examined molecule per TNBC and HR-positive patient is shown in Figure 5C.

\section{CTC phenotype and clinical outcome}

After a median follow-up period of 55 months (range, 16- 88 months), 10 (21.3\%) patients with early TNBC presented disease relapse. Seven out of 21 (33.3\%) of patients with $\mathrm{CK}^{+} \mathrm{ER}$ - CTCs relapsed; the incidence of relapse was significantly increased $(p=0.048)$ in patients with $\mathrm{CK}+\mathrm{ER}-\mathrm{CTCs}$ at baseline compared to patients without this CTC subpopulation before the initiation of adjuvant chemotherapy. Similarly, seven out of 19 patients (36.8\%) with CTCs bearing the CK+HER2phenotype at baseline relapsed during the follow-up period compared to 2 out of $26(7.6 \%)$ patients who had not this phenotype $(\mathrm{p}=0.044)$. Cox regression analysis revealed shorter DFI ( $p=0.04$; HR: $1.035 ; \mathrm{Cl}$ : 1.002-1.070) for patients harvesting $\mathrm{CK}+\mathrm{PR}-\mathrm{CTC}$ in their blood. There was no correlation between DFI and the other CTC subpopulations (data not shown).

Similarly, only the $\mathrm{CK}+\mathrm{PR}$ - phenotype before adjuvant treatment was associated with a reduced OS ( $p=0.034$; HR:1.04; CI: 1.003-1.075. Table 3); it should be mentioned that, during the follow up period, there were no deaths among patients lacking this phenotype.

\section{DISCUSSION}

Treatment of patients with TNBC remains challenging due to the absence of effective targeted therapies that could improve clinical outcome. However, it is widely accepted that TNBC are often characterized by an extremely high heterogeneity [24]. Since it is difficult to recognize the "hazardous" subpopulation that are the origin of metastases in breast cancer, it was of interest to extensively characterize the CTCs of TNBC patients. The present study phenotypically characterized the CTCs in TNBC patients and, more especially, evaluated the expression of ER, PR, HER2 and EGFR on these cells. The presented data clearly indicate that ER and PR were expressed on CTCs detected in $24.4 \%$ of patients with early stage disease.. Similarly, CK+HER2+ CTCs could be detected in $20 \%$ of TNBC patients with early stage disease; conversely, CK+EGFR+ CTCs (40\%) were frequently detected in these patients and clearly predominated over the other phenotypes. This observation seems to indicate that in TNBC patients the phenotype of CTCs reflects the well known expression of EGFR in the primary tumor cells [25].

The presence of $\mathrm{ER}+\mathrm{CK}+$ at baseline correlated significantly with the presence of $\mathrm{PR}+\mathrm{CK}+(\mathrm{p}=0.016)$, implying that these phenotypes are frequently observed in the same patient. Conversely, there was no statistical correlation between the expression of ER or PR and EGFR on CTCs, suggesting that these molecules are expressed in different subpopulations. This notion was further confirmed by the absence of co-expression of ER or PR and EGFR in triple staining experiments.

An interesting observation in the current study was the increased incidence of disease relapse in patients with CK+ER-CTCs; this finding strongly suggests that the absence of HR expression in CTCs is a poor prognostic factor in TNBC patients. Moreover, survival analysis revealed that patients with CTCs bearing the CK+PRphenotype before treatment experienced a significantly decreased DFI $(p=0.04)$ and OS $(p=0.032)$ suggesting that these cells could be more aggressive in terms of metastatic potential. These observations seem to be in agreement with the worse clinical outcome of patients with HRnegative tumors [26-29]. However, these results are only exploratory, retrospectively performed and need to be confirmed in a prospective study including a larger group of patients. In addition, we have to mention that there is a possibility to underestimate the total number of CTCs because of the low CK8/18 expression in TNBC patients.

In the present study it was also of interest to investigate the different subpopulations of CTCs surviving adjuvant chemotherapy. Interestingly, chemotherapy resulted in a reduced frequency of HER2- but not of ER- or PR-expressing CTCs. This observation suggests that chemotherapy cannot eliminate the different subpopulations of CTCs with the same efficacy. This assumption strongly suggests the need for additional therapeutic approaches in order to eliminate these chemotherapy-resistant CTCs. In line with this observation, it has been shown that CTCs could have EMT and stem cell properties [30-33]. These phenotypes are potentially resistant to common chemotherapy as it has been recently reported in patients receiving neoadjuvant treatment $\mathrm{t}$ [34].

It is also noteworthy that the incidence of $\mathrm{CK}+\mathrm{HER} 2+$-expressing CTCs in patients with metastatic TNBC was significantly increased compared to patients with early stage disease; this finding clearly suggests that $\mathrm{CK}+\mathrm{HER} 2+$ is an aggressive phenotype that predominates during disease evolution even in TNBC patients. The potential to target $\mathrm{CK}+\mathrm{HER} 2+\mathrm{CTCs}$ with lapatinib or trastuzumab, has been recently reported $[35,36]$. These observations suggest that therapies directed against specific targets could be necessary in order to eliminate CK+HER2+ chemotherapy-resistant CTCs.

Finally, the comparative distribution of the evaluated CTC subpopulations in $\mathrm{HR}(+)$ and in TNBC patients has shown that ER- and PR-positive phenotypes are significantly increased in HR-positive breast cancer patients.. Moreover, HER2 expression on CTCs was higher in $\mathrm{HR}(+)$ compared to TNBC patients, confirming the observation that HER2 can be present on CTCs irrespectively of the phenotype of the primary tumor $[14,36]$. 
Table 3: Survival analysis in TNBC patients before and after chemotherapy

\begin{tabular}{|c|c|c|c|c|c|c|c|c|c|c|c|c|}
\hline \multirow[t]{3}{*}{$\begin{array}{l}\text { CTCs' } \\
\text { PHENOTYPE }\end{array}$} & \multicolumn{3}{|c|}{$\begin{array}{c}\text { BEFORE } \\
\text { CHEMOTHERAPY }\end{array}$} & \multicolumn{4}{|c|}{$\begin{array}{c}\text { AFTER } \\
\text { CHEMTHERAPY }\end{array}$} & \multicolumn{2}{|c|}{$\begin{array}{c}\text { BEFORE } \\
\text { CHEMOTHERAPY }\end{array}$} & \multicolumn{3}{|c|}{ AFTER CHEMTHERAPY } \\
\hline & \multicolumn{6}{|c|}{ OS } & \multicolumn{6}{|c|}{ DFS } \\
\hline & $p$ values & $\begin{array}{l}\text { Median } O S \\
\quad \text { (range) }\end{array}$ & HR & $\begin{array}{c}p \\
\text { values }\end{array}$ & $\begin{array}{l}\text { Median OS } \\
\quad \text { (range) }\end{array}$ & HR & $p$ values & Median OS (range) & HR & $p$ values & $\begin{array}{l}\text { Median } O S \\
\quad \text { (range) }\end{array}$ & HR \\
\hline $\mathbf{E R}+\mathbf{C K}+$ & 0,705 & $\begin{array}{c}76,2 \\
(76,6-94,5)\end{array}$ & 0,854 & 0,721 & $\begin{array}{c}64,3 \\
(46,1-82,54)\end{array}$ & 1,21 & 0,52 & $74,25(58,9-89,6)$ & 0,892 & 0,556 & $64,3(46,1-82,5)$ & 0,716 \\
\hline ER-CK+ & 0,523 & $\begin{array}{c}73,5 \\
(61,3-85,7)\end{array}$ & 0,878 & 0,657 & $\begin{array}{c}67,5 \\
(54,9-80,2)\end{array}$ & 0,912 & 0,534 & $89,6(48,4-130,9)$ & 0,955 & 0,582 & $60,4(47,8-73)$ & 1,024 \\
\hline $\mathbf{P R}+\mathrm{CK}+$ & 0,495 & $\begin{array}{c}82 \\
(71,8-92,1)\end{array}$ & 0,588 & 0,127 & $\begin{array}{c}54 \\
(37-70,9)\end{array}$ & 2,018 & 0,517 & $80(61,9-98,1)$ & 0,87 & 0,39 & $54(37-70)$ & 1,481 \\
\hline PR-CK+ & 0,034 & $\begin{array}{c}55 \\
(16-94)\end{array}$ & 1,038 & 0,816 & $\begin{array}{c}53,5 \\
(16-80)\end{array}$ & 0,957 & 0.04 & $66(42,8-133,2)$ & 1,035 & 0,627 & $61,2(51,1-71,2)$ & 1,054 \\
\hline HER2+CK+ & 0,647 & $\begin{array}{c}74,6 \\
(61,5-97,7)\end{array}$ & 0,887 & 0,682 & $\begin{array}{c}54,5 \\
(52-57)\end{array}$ & 0,265 & 0,546 & $62,071(52,2-71,9)$ & 0,921 & 0,484 & $56(55-57)$ & 0,182 \\
\hline HER2-CK+ & 0,331 & $\begin{array}{c}74,8 \\
(61,7-87,9)\end{array}$ & 1,239 & 0,707 & $\begin{array}{c}73,3 \\
(65,9-80,8)\end{array}$ & 0,923 & 0,255 & $90,1(47,9-132,1)$ & 0,218 & 0,698 & $58,7(50,1-67,4)$ & 1,039 \\
\hline $\mathbf{E G F R}+\mathbf{C K}+$ & 0,145 & $\begin{array}{c}79,7 \\
(65,5-93,9)\end{array}$ & 1,044 & 0,157 & $\begin{array}{c}84,4 \\
(77,7-91,2)\end{array}$ & 0,253 & 0,254 & $101,4(61,1-141,8)$ & 1,031 & 0,127 & $76,4(63,1-89,7)$ & 0,439 \\
\hline EGFR-CK+ & 0,534 & $\begin{array}{c}76,5 \\
(61,9-91,1)\end{array}$ & 1,196 & 0,362 & $\begin{array}{c}61 \\
(39-67)\end{array}$ & 0,06 & 0,232 & $74,5(58,1-90,9)$ & 1,248 & 0,2 & $77,7(62,7-92,6)$ & 0,401 \\
\hline
\end{tabular}

\section{MATERIALS AND METHODS}

\section{Patient samples and cytospin preparation}

A total of 76 CTC-positive patients with early or metastatic breast cancer were included in the present study; 55 patients had TNBC ( $\mathrm{n}=45$ with early and $\mathrm{n}=10$ with metastatic disease) and 21 had $\mathrm{HR}(+)$ early breast cancer. Patients' characteristics are shown in Table 4. These patients had been identified after routine screening performed for the presence of $\mathrm{CK}(+) / \mathrm{CD} 45(-)$ cells on PMBC cytospins. Ten female normal blood donors were also included as negative controls. Peripheral blood (10 $\mathrm{ml}$ in EDTA) was obtained beforethe initiation of adjuvant (usually within 3-4 weeks after primary surgery) or first line therapy for metastatic disease. TNBC patients with early disease were also evaluated at the end of adjuvant chemotherapy. All blood samples were obtained in the middle of vein puncture after the first $5 \mathrm{ml}$ of blood were discarded. These precautions were undertaken in order to avoid contamination of the blood sample with epithelial cells from the skin during sample collection. All patients gave their informed consent to participate in the study, which has been approved by the Ethics and Scientific Committees of our Institution.

Peripheral blood mononuclear cells (PBMC) were isolated with Ficoll-Hypaque density gradient $(\mathrm{d}=1,077 \mathrm{gr} /$ mol) centrifugation at $1800 \mathrm{rpm}$ for $30 \mathrm{~min}$. PBMCs were washed three times with PBS and centrifuged at 1500rpm for $10 \mathrm{~min}$. Aliquots of 250.000 cells were centrifuged at $2000 \mathrm{rpm}$ for $2 \mathrm{~min}$ on glass slides. Cytospins were dried up and stored at $-80^{\circ} \mathrm{C}$. Four to five slides were evaluated for each patient.

\section{Cell cultures}

For control experiments two different breast cancer cell lines, MCF7 and SKBR3 (both obtained from the ATCC; American Type Culture Collection, USA), were used. The MCF7 mammary adenocarcinoma cells were cultured in (v/v) 1:1 Dulbecco's Modified Eagle Medium (DMEM)/Ham's F12 medium (GIBCO-BRL Co, MD, USA) supplemented with $10 \%$ fetal bovine serum (FBS) (GIBCO-BRL), 2mM L-glutamine (GIBCO-BRL) $30 \mathrm{mM}$ $\mathrm{NaHCOB}_{3 \mathrm{~B}}, 16 \mathrm{ng} / \mathrm{ml}$ insulin and $50 \mathrm{mg} / \mathrm{ml}$ penicilline/ streptomycin (GIBCO-BRL). SKBR3 cells were used as positive control for HER2 and EGFR expression. SKBR3 cells were cultured in McCoy's (GIBCO-BRL) enriched with $10 \%$ fetal bovine serum and $2 \mathrm{mM}$ L-glutamine supplemented with $50 \mathrm{mg} / \mathrm{ml}$ penicilline/streptomycin. Cells were maintained in a humidified atmosphere of 5\% $\mathrm{COB}_{2 \mathrm{~B}}-95 \%$ air.

Sub-cultivation for all cell lines was performed with $0.25 \%$ trypsin and $5 \mathrm{mM}$ EDTA. All experiments were performed during the logarithmic growth phase. 15$20 \mathrm{~h}$ before each experiment and cells were transferred to serum-starved medium containing only L-glutamine, $\mathrm{NaHCOB}_{3 \mathrm{~B}}$ and antibiotics. 
Table 4: Patients' characteristics

\section{Early disease (45 TNBC patients)}

Early disease (21HR-positive)

\begin{tabular}{|c|c|c|c|c|c|}
\hline Age & & Age & & Age & \\
\hline \multirow[t]{2}{*}{ Median, range } & $53(35-77)$ & Median, range & $57(37-84)$ & Median, range & $66(45-82)$ \\
\hline & $N$ & & $N$ & & $N$ \\
\hline Menopausal status & & Menopausal status & & $\begin{array}{l}\text { Menopausal } \\
\text { status }\end{array}$ & \\
\hline Premenopausal & $11(24.4 \%)$ & Premenopausal & $5(23.8 \%)$ & Premenopausal & $2(20 \%)$ \\
\hline Postmenopausal & $28(62.2 \%)$ & Postmenopausal & $12(57.1 \%)$ & Postmenopausal & $7(70 \%)$ \\
\hline Unknown & $6(13.3 \%)$ & Unknown & $4(19 \%)$ & Unknown & $1(10 \%)$ \\
\hline Tumor size & & Tumor size & & Disease sites & \\
\hline pT1 & $15(33.3 \%)$ & pT1 & $2(9.5 \%)$ & 1 & $6(60 \%)$ \\
\hline pT2 & $19(42.2 \%)$ & pT2 & $6(28.6 \%)$ & 2 & $1(10 \%)$ \\
\hline pT3 & $1(2.2 \%)$ & pT3 & $6(28.6 \%)$ & 3 & $1(10 \%)$ \\
\hline \multirow[t]{2}{*}{ Unknown } & $10(22 \%)$ & Unknown & $8(38 \%)$ & $\geq 4$ & $1(10 \%)$ \\
\hline & & & & Unknown & $1(10 \%)$ \\
\hline Lymph node status & & Lymph node status & & $\begin{array}{l}\text { Predominantly } \\
\text { visceral disease }\end{array}$ & \\
\hline Node-negative & $23(51.1 \%)$ & Node-negative & $3(14.3 \%)$ & Yes & $2(20 \%)$ \\
\hline Node-positive & $12(26.7 \%)$ & Node-positive & $12(57.1 \%)$ & No & $8(80 \%)$ \\
\hline Unknown & $10(22 \%)$ & Unknown & $6(28.6 \%)$ & Unknown & $0(0 \%)$ \\
\hline Histologic grade & & Histologic grade & & $\begin{array}{l}\text { Primary breast } \\
\text { cancer }\end{array}$ & \\
\hline Grade 1 & $1(2.2 \%)$ & Grade 1 & $0(0 \%)$ & Adjuvant & $3(30 \%)$ \\
\hline Grade 2 & $8(17.8 \%)$ & Grade 2 & $6(28.6 \%)$ & Metastatic & $6(60 \%)$ \\
\hline Grade 3 & $27(60 \%)$ & Grade 3 & $9(42.9 \%)$ & Unknown & $1(10 \%)$ \\
\hline Grade 4 & $2(4.4 \%)$ & Grade 4 & $1(4.8 \%)$ & & \\
\hline Unknown & $7(15.5 \%)$ & Unknown & $5(23.8 \%)$ & & \\
\hline ER/PR tumor status & & ER/PR tumor status & & $\begin{array}{l}\text { ER/PR tumor } \\
\text { status }\end{array}$ & \\
\hline Positive & $0(0 \%)$ & Positive & $21(100 \%)$ & Positive & $0(0 \%)$ \\
\hline Negative & $45(100 \%)$ & Negative & $0(0 \%)$ & Negative & $10(100 \%)$ \\
\hline Unknown & $0(0 \%)$ & Unknown & $0(0 \%)$ & Unknown & $0(0 \%)$ \\
\hline HER2 tumor status & & HER2 tumor status & & $\begin{array}{l}\text { HER2 tumor } \\
\text { status }\end{array}$ & \\
\hline Positive* & $0(0 \%)$ & Positive* & $0(0 \%)$ & Positive* & $0(0 \%)$ \\
\hline Negative & $45(100 \%)$ & Negative & $21(100 \%)$ & Negative & $10(100 \%)$ \\
\hline Unknown & $0(0 \%)$ & Unknown & $0(0 \%)$ & Unknown & $0(0 \%)$ \\
\hline
\end{tabular}

Metastatic TNBC patients (10 Patients) 


\section{Confocal laser scanning and ARIOL system Microscopy}

The A45-B/B3 mouse antibody (Micromet Munich, Germany) which detect the CK8, CK18 and CK19 was used in order to evaluate the expression of cytokeratins on PBMCs cytospins; The A45-B/ B3 antibody is commonly used for CTCs evaluation [17] in breast cancer, however we have to mention that TN tumors frequently express lower level of 8/18 [37]. Cytospins were also double stained with anti-CD45 (common leukocyte antigen) antibody to exclude possible ectopic expression of cytokeratins by hematopoietic cells. In cytospins of the same patients the expression of ER (Santa Cruz, Santa Cruz, CA, USA), PR (Santa Cruz), HER2 (Cell Signaling, Boston, US) and EGFR (Santa Cruz), was also evaluated using double staining experiments. The antibodies against the ER and PR were appropriate for nuclear staining according to the manufacturer.

PBMC cytospins were fixed with cold aceton:methanol 9:1 for 20min and stained for cytokeratin with a pancytokeratin antibody as mentioned above. Subsequently, the same slide was stained with ER, PR, HER2 or EGFR antibodies for $1 \mathrm{~h}$. Cells were then incubated with the corresponding secondary antibodies for $45 \mathrm{~min}$. Slides were analyzed using either confocal laser scanning microscopy (Leica Lasertechnik, Heidelberg, Germany) or the semi-automated ARIOL system [16, 17].

Positive and negative controls were included in each experiment. Negative controls were prepared by omitting the corresponding primary antibodies. Furthermore, MCF7 breast cancer cells were used as negative controls for HER2 and EGFR expression and SKBR3 cells served as negative controls for ER and PR expression. The cyto-morphological criteria proposed by Meng et al [38] were employed in order to characterize a CK-positive cell as a CTC. All the CTCs displaying a HER2 staining intensity higher than that of MCF7 and PBMCs, were considered as HER2-positive as it has been previously reported $[16,17]$. The intensity of HER2 was also quantified in MCF7, SKBR3 and in CTCs isolated from 5 TNBC patients using ARIOL system analysis. For ER and PR only the nuclear staining was accepted as positive irrespectively of the intensity. Finally, for EGFR, intensity higher than that of PBMCs and MCF7 (negative controls) was considered as positive.

\section{Immunomagnetic separation of CTCs}

In patients with detectable CTCs expressing at least 2 among the ER, PR, HER2 or EGFR molecules, a negative immunomagnetic selection for CTC isolation was performed according to Naume et al (1998) in a separate blood sample. Briefly, $100 \mu$ l of CELLection beads coated with anti-CD45 monoclonal antibody (Dynal, Invitrogen, Carlsbad, CA, USA) were added in $10^{7 \mathrm{p}} / \mathrm{ml}$ PBMCs in $\mathrm{PBS} / 0.1 \% \mathrm{BSA} / 2 \mathrm{mM}$ EDTA. PBMCs were isolated from
$20 \mathrm{ml}$ of blood using Ficoll density gradient centrifugation. After incubation for $30 \mathrm{~min}$ at $4{ }^{\circ} \mathrm{C}$, the supernatant was transferred in FBS-coated tubes and cells were cytocentrifuged at $2000 \mathrm{rpm}$ for $2 \mathrm{~min}$ on glass slides.

\section{Triple immunofluorescence}

Triple immunofluoresence staining experiments for CK/ER/HER2, CK/ER/EGFR, CK/PR/HER2 and CK/PR/ EGFR were performed on PBMC cytospins prepared after immunomagnetic separation. Cells were initially fixed with cold aceton:methanol 9:1. After blocking with PBS supplemented with $10 \%(\mathrm{v} / \mathrm{v})$ FBS for $30 \mathrm{~min}$, cells were incubated with the corresponding antibodies for $45 \mathrm{~min}$ each. Zenon technology (FITC-conjugated IGg1 antibody) (Molecular Probes, Invitrogen, Carlsbad, CA, USA) was used for $\mathrm{CK}$ detection with the A45-B/B3 antibody. Zenon antibodies were prepared within 30min before use.

HER2 (Oncogene, Dermstadt, Germany) was detected using anti-mouse antibody labelled with Alexa 555 (Molecular Probes), whereas the ER and PR were detected with the previously described anti-rabbit antibodies and Alexa 633 fluorochrome (Molecular Probes). EGFR was detected with anti-mouse (Santa Cruz) antibody and Alexa 555 fluorochrome. Finally, cells were stained with DAPI conjugated with antifade.

\section{Statistical analysis}

Disease-Free Interval (DFI), was defined as the time from the initiation of adjuvant treatment until the day of the first evidence of disease recurrence or death from any cause and overall survival (OS) as the time from disease diagnosis to death from any cause. ProgressionFree Survival (PFS) in patients with metastatic disease was defined from the initiation of front-line treatment until disease relapse or death. Kaplan-Meier curves and Cox regression analysis for PFS and OS were compared using the log-rank test to provide a univariate assessment of the prognostic value of selected clinical risk factors. Clinico-pathologic factors such as menopausal status, tumor size, number of involved lymph nodes, estrogen and progesterone receptor (ER) status and HER-2 status were also evaluated in univariate analysis. Variables that were found to be significant at the univariate analysis were then entered in a stepwise multivariate Cox proportional hazards regression model to identify those with independent prognostic information. All statistical tests were performed at the $5 \%$ level of significance. SPSS version 15 (SPSS Inc, Chicago, IL) statistical software was used for the analysis.

\section{CONCLUSIONS}

CTCs isolated isolated from TNBC patients express ER, PR and HER2 although the freaquency is significantly lower compared to those detected in patients with HR- 
positive tumors. The incidence of $\mathrm{CK}+\mathrm{HER} 2+\mathrm{CTCs}$ is increased in metastatic TNBC patients suggesting that this phenotype prevails during disease evolution. The $\mathrm{CK}+\mathrm{EGFR}+\mathrm{CTC}$ phenotype was the most frequently detected among TNBC patients both before and after the completion of adjuvant chemotherapy; subsequent studies could elucidate whether EGFR could represent an attractive therapeutic target in patients with metastatic TNBC.

\section{CONFLICTS OF INTEREST}

The authors declare that they have no conflicts of Interest.

\section{GRANT SUPPORT}

This work partly by the Hellenic Oncology Research Group (HORG), the Greek General Secretary of Research and Technology grant Oncoseed PN 3175, the Cretan Association for Biomedical Research (CABR), and the International Scientific Partnership Program ISPP at King Saud University for funding this research work through (ISPP\#009).

\section{REFERENCES}

1. Foulkes WD, Smith IE, Reis-Filho JS. Triple-negative breast cancer. N Engl J Med. 2010; 363: 1938-1948.

2. Irvin WJ, Jr., Carey LA. What is triple-negative breast cancer? Eur J Cancer. 2008; 44: 2799-2805.

3. Perou CM, Sorlie T, Eisen MB, van de Rijn M, Jeffrey SS, Rees CA, Pollack JR, Ross DT, Johnsen H, Akslen LA, Fluge O, Pergamenschikov A, Williams C, Zhu SX, Lonning PE, Borresen-Dale AL, Brown PO, Botstein D. Molecular portraits of human breast tumours. Nature. 2000; 406: 747-752.

4. Nielsen TO, Hsu FD, Jensen K, Cheang M, Karaca G, Hu Z, Hernandez-Boussard T, Livasy C, Cowan D, Dressler L, Akslen LA, Ragaz J, Gown AM, Gilks CB, van de Rijn M, Perou CM. Immunohistochemical and clinical characterization of the basal-like subtype of invasive breast carcinoma. Clin Cancer Res. 2004; 10: 5367-5374.

5. Rakha EA, Elsheikh SE, Aleskandarany MA, Habashi HO, Green AR, Powe DG, El-Sayed ME, Benhasouna A, Brunet JS, Akslen LA, Evans AJ, Blamey R, Reis-Filho JS, Foulkes WD, Ellis IO. Triple-negative breast cancer: distinguishing between basal and nonbasal subtypes. Clin Cancer Res. 2009; 15: 2302-2310.

6. Rodriguez-Pinilla SM, Sarrio D, Honrado E, Hardisson D, Calero F, Benitez J, Palacios J. Prognostic significance of basal-like phenotype and fascin expression in node-negative invasive breast carcinomas. Clin Cancer Res. 2006; 12: 1533-1539.

7. Rodriguez-Pinilla SM, Sarrio D, Honrado E, MorenoBueno G, Hardisson D, Calero F, Benitez J, Palacios J.
Vimentin and laminin expression is associated with basallike phenotype in both sporadic and BRCA1-associated breast carcinomas. J Clin Pathol. 2007; 60: 1006-1012.

8. Hudis CA, Gianni L. Triple-negative breast cancer: an unmet medical need. Oncologist. 2011; 16 Suppl 1: 1-11.

9. Gucalp A, Sparano JA, Caravelli J, Santamauro J, Patil S, Abbruzzi A, Pellegrino C, Bromberg J, Dang C, Theodoulou M, Massague J, Norton L, Hudis C, Traina TA. Phase II trial of saracatinib (AZD0530), an oral SRC-inhibitor for the treatment of patients with hormone receptor-negative metastatic breast cancer. Clin Breast Cancer. 2011; 11: 306-311.

10. Cristofanilli M, Hayes DF, Budd GT, Ellis MJ, Stopeck A, Reuben JM, Doyle GV, Matera J, Allard WJ, Miller MC, Fritsche HA, Hortobagyi GN, Terstappen LW. Circulating tumor cells: a novel prognostic factor for newly diagnosed metastatic breast cancer. J Clin Oncol. 2005; 23: 1420-1430.

11. Stathopoulou A, Vlachonikolis I, Mavroudis D, Perraki M, Kouroussis C, Apostolaki S, Malamos N, Kakolyris S, Kotsakis A, Xenidis N, Reppa D, Georgoulias V. Molecular detection of cytokeratin-19-positive cells in the peripheral blood of patients with operable breast cancer: evaluation of their prognostic significance. J Clin Oncol. 2002; 20: 3404-3412.

12. Xenidis N, Perraki M, Kafousi M, Apostolaki S, Bolonaki I, Stathopoulou A, Kalbakis K, Androulakis N, Kouroussis C, Pallis T, Christophylakis C, Argyraki K, Lianidou ES, Stathopoulos S, Georgoulias V, Mavroudis D. Predictive and prognostic value of peripheral blood cytokeratin-19 mRNA-positive cells detected by real-time polymerase chain reaction in node-negative breast cancer patients. $\mathrm{J}$ Clin Oncol. 2006; 24: 3756-3762.

13. Kaiser J. Medicine. Cancer's circulation problem. Science. 2010; 327: 1072-1074.

14. Ignatiadis M, Rothe F, Chaboteaux C, Durbecq V, Rouas G, Criscitiello C, Metallo J, Kheddoumi N, Singhal SK, Michiels S, Veys I, Rossari J, Larsimont D, Carly B, Pestrin M, Bessi S, Buxant F, Liebens F, Piccart M, Sotiriou C. HER2-positive circulating tumor cells in breast cancer. PLoS One. 2011; 6: e15624.

15. Kallergi G, Agelaki S, Papadaki MA, Nasias D, Matikas A, Mavroudis D, Georgoulias V. Expression of truncated human epidermal growth factor receptor 2 on circulating tumor cells of breast cancer patients. Breast Cancer Res. 2015; $17: 113$.

16. Kallergi G, Mavroudis D, Georgoulias V, Stournaras C. Phosphorylation of FAK, PI-3K, and impaired actin organization in CK-positive micrometastatic breast cancer cells. Mol Med. 2007; 13: 79-88.

17. Kallergi G, Agelaki S, Kalykaki A, Stournaras C, Mavroudis D, Georgoulias V. Phosphorylated EGFR and PI3K/Akt signaling kinases are expressed in circulating tumor cells of breast cancer patients. Breast Cancer Res. 2008; 10: R80.

18. Klein CA, Blankenstein TJ, Schmidt-Kittler O, Petronio M, Polzer B, Stoecklein NH, Riethmuller G. Genetic 
heterogeneity of single disseminated tumour cells in minimal residual cancer. Lancet. 2002; 360: 683-689.

19. Punnoose EA, Atwal SK, Spoerke JM, Savage H, Pandita A, Yeh RF, Pirzkall A, Fine BM, Amler LC, Chen DS, Lackner MR. Molecular biomarker analyses using circulating tumor cells. PLoS One. 2010; 5: e12517.

20. Peeters DJ, van Dam PJ, Van den Eynden GG, Rutten A, Wuyts H, Pouillon L, Peeters M, Pauwels P, Van Laere SJ, van Dam PA, Vermeulen PB, Dirix LY. Detection and prognostic significance of circulating tumour cells in patients with metastatic breast cancer according to immunohistochemical subtypes. Br J Cancer. 2014; 110: 375-383.

21. Karhade M, Hall C, Mishra P, Anderson A, Kuerer H, Bedrosian I, Krishnamurthy S, Lucci A. Circulating tumor cells in non-metastatic triple-negative breast cancer. Breast Cancer Res Treat. 2014; 147: 325-333.

22. Hall C, Karhade M, Laubacher B, Anderson A, Kuerer H, DeSynder S, Lucci A. Circulating Tumor Cells After Neoadjuvant Chemotherapy in Stage I-III Triple-Negative Breast Cancer. Ann Surg Oncol. 2015; 22 Suppl 3: S552-558.

23. Magbanua MJ, Carey LA, DeLuca A, Hwang J, Scott JH, Rimawi MF, Mayer EL, Marcom PK, Liu MC, Esteva FJ, Park JW, Rugo HS. Circulating tumor cell analysis in metastatic triple-negative breast cancers. Clin Cancer Res. 2015; 21: 1098-1105.

24. Torres L, Ribeiro FR, Pandis N, Andersen JA, Heim S, Teixeira MR. Intratumor genomic heterogeneity in breast cancer with clonal divergence between primary carcinomas and lymph node metastases. Breast Cancer Res Treat. 2007; 102: 143-155.

25. Siziopikou KP, Cobleigh M. The basal subtype of breast carcinomas may represent the group of breast tumors that could benefit from EGFR-targeted therapies. Breast. 2007; 16: 104-107.

26. Sorlie T, Perou CM, Tibshirani R, Aas T, Geisler S, Johnsen H, Hastie T, Eisen MB, van de Rijn M, Jeffrey SS, Thorsen T, Quist H, Matese JC, Brown PO, Botstein D, Lonning PE, Borresen-Dale AL. Gene expression patterns of breast carcinomas distinguish tumor subclasses with clinical implications. Proc Natl Acad Sci U S A. 2001; 98: 10869-10874.

27. Sorlie T, Tibshirani R, Parker J, Hastie T, Marron JS, Nobel A, Deng S, Johnsen H, Pesich R, Geisler S, Demeter J, Perou CM, Lonning PE, Brown PO, Borresen-Dale AL, Botstein D. Repeated observation of breast tumor subtypes in independent gene expression data sets. Proc Natl Acad Sci U S A. 2003; 100: 8418-8423.

28. Sotiriou C, Neo SY, McShane LM, Korn EL, Long PM, Jazaeri A, Martiat P, Fox SB, Harris AL, Liu ET. Breast cancer classification and prognosis based on gene expression profiles from a population-based study. Proc Natl Acad Sci U S A. 2003; 100: 10393-10398.
29. Potemski P, Kusinska R, Watala C, Pluciennik E, Bednarek AK, Kordek R. Prognostic relevance of basal cytokeratin expression in operable breast cancer. Oncology. 2005; 69: 478-485.

30. Kasimir-Bauer S, Hoffmann O, Wallwiener D, Kimmig R, Fehm T. Expression of stem cell and epithelialmesenchymal transition markers in primary breast cancer patients with circulating tumor cells. Breast Cancer Res. 2012; 14: R15.

31. Papadaki MA, Kallergi G, Zafeiriou Z, Manouras L, Theodoropoulos PA, Mavroudis D, Georgoulias V, Agelaki S. Co-expression of putative stemness and epithelial-tomesenchymal transition markers on single circulating tumour cells from patients with early and metastatic breast cancer. BMC Cancer. 2014; 14: 651.

32. Kallergi G, Papadaki MA, Politaki E, Mavroudis D, Georgoulias V, Agelaki S. Epithelial to mesenchymal transition markers expressed in circulating tumour cells of early and metastatic breast cancer patients. Breast Cancer Res. 2011; 13: R59.

33. Aktas B, Tewes M, Fehm T, Hauch S, Kimmig R, KasimirBauer S. Stem cell and epithelial-mesenchymal transition markers are frequently overexpressed in circulating tumor cells of metastatic breast cancer patients. Breast Cancer Res. 2009; 11: R46.

34. Kasimir-Bauer S, Bittner AK, Konig L, Reiter K, Keller T, Kimmig R, Hoffmann O. Does primary neoadjuvant systemic therapy eradicate minimal residual disease? Analysis of disseminated and circulating tumor cells before and after therapy. Breast Cancer Res. 2016; 18: 20.

35. Agelaki S, Kalykaki A, Markomanolaki H, Papadaki MA, Kallergi G, Hatzidaki D, Kalbakis K, Mavroudis D, Georgoulias V. Efficacy of Lapatinib in Therapy-Resistant HER2-Positive Circulating Tumor Cells in Metastatic Breast Cancer. PLoS One. 2015; 10: e0123683.

36. Georgoulias V, Bozionelou V, Agelaki S, Perraki M, Apostolaki S, Kallergi G, Kalbakis K, Xyrafas A, Mavroudis D. Trastuzumab decreases the incidence of clinical relapses in patients with early breast cancer presenting chemotherapy-resistant CK-19mRNA-positive circulating tumor cells: results of a randomized phase II study. Ann Oncol. 2012; 23: 1744-1750.

37. Yehiely F, Moyano JV, Evans JR, Nielsen TO, Cryns VL. Deconstructing the molecular portrait of basal-like breast cancer. Trends Mol Med. 2006; 12: 537-544.

38. Meng S, Tripathy D, Frenkel EP, Shete S, Naftalis EZ, Huth JF, Beitsch PD, Leitch M, Hoover S, Euhus D, Haley B, Morrison L, Fleming TP, Herlyn D, Terstappen LW, Fehm T, Tucker TF, Lane N, Wang J, Uhr JW. Circulating tumor cells in patients with breast cancer dormancy. Clin Cancer Res. 2004; 10: 8152-8162. 